\title{
Extraction optimization of luteolin, antioxidant compound, from Arachis hypogaea L. hull using response surface methodology
}

\author{
Inonge Noni Siziya ${ }^{1}$, Dong-Ho Seo ${ }^{1}$, Hyeonhwa $\mathrm{Oh}^{1}$, Hyeon-Jin $\mathrm{Kang}^{2}$, Young-Soo Kim ${ }^{1 *}$ \\ ${ }^{1}$ Department of Food Science and Technology, Jeonbuk National University, Jeonju 54896, Korea \\ ${ }^{2}$ Microbial Institute for Fermentation Industry (MIFI), Sunchang 56048, Korea
}

\begin{abstract}
Luteolin is the most abundant phytochemical phenolic compound contained within peanut hulls and has broad pharmacological characteristics and high bioavailability. In this study, the extraction conditions for luteolin from peanut hulls were optimized. The effects of methanol concentration and reaction temperature on luteolin solubility were determined using the central composite design (CCD) under response surface methodology. Luteolin content within in the extracts increased with increasing temperature and organic solvent-to-water ratios. The optimal conditions for luteolin extraction were $81^{\circ} \mathrm{C}$ and $87.5 \%$ methanol for a predicted extraction value of $174.51 \mathrm{mg} / 100 \mathrm{~g}$, which was within $1.25 \%$ of the experimental value of $172.35 \mathrm{mg} / 100 \mathrm{~g}$, confirming the predicted model. Additionally, compared to conventional stining, the luteolin content of reflux-extracted peanut hull had a higher extraction efficiency by $\mathbf{4 2 . 5 0 \%}$. The antioxidant compound contents and antioxidant capacity of the extracts were also determined, with the effects of temperature and solvent concentration increasing along with the extracted luteolin. In this study, CCD optimized the conditions for obtaining luteolin from peanut hulls, suggesting that the improved extraction efficiency of the bioactive compound can expand the use of peanut shells in the nutraceutical and food industries.
\end{abstract}

Key words : peanut hull, central composite design, luteolin, extraction, response surface methodology

Introduction

Recently, in order to increase sustainability in processing industries, focus has been placed on the exhaustive use of fruit and vegetable waste biomass, particularly from plant parts such as seeds, husks and roots. Among them, peanut hulls have shown considerable applications in multiple industries and a number of ventures have been undertaken in order to increase their use (Zhao et al., 2012). Peanuts (Arachis hypogaea L.) are a major international cash crop as the kernel is used for a variety of products, such as snacks, peanut butter and oil (Lee et al., 2011). The skins and hulls, however, are often taken as agricultural waste; used in compost, fuel, feed or simply abandoned (Qiu et al.,
2018; Win et al., 2011).

Approximately 230-300 g of hulls are produced per kilogram of peanut and the increasing annual production gives rise to over 13.5 million metric tons of the shells (Zhao et al., 2012). Peanuts hulls are composed of cellulose (40.5\%), lignin (26.4\%), hemicelluloses (14.7\%) trace macro and micro-nutrients, as well as phenolic compounds such as eriodictyol, 5,7-dihydroxychromone, and luteolin (Lee et al., 2008; Qiu et al., 2018; Rivilli et al., 2012). Luteolin is the most abundant phytochemical extract, chemicals from plant origins, of the phenolic compounds in peanuts hulls and it is a flavonoid with various pharmacological and antioxidant properties (Adhikari et al., 2018; Lee et al., 2008). Moreover, it has been shown to have high bioavailability when sourced

*Corresponding author. E-mail : ykim@jbnu.ac.kr, Phone : +82-63-270-2569, Fax : +82-63-270-2572

Received 19 October 2020; Revised 28 December 2020; Accepted 29 December 2020.

Copyright (c) The Korean Society of Food Preservation.

This is an Open Access article distributed under the terms of the Creative Commons Attribution Non-Commercial License (http://creativecommons.org/licenses/by-nc/4.0) which permits unrestricted non-commercial use, distribution, and reproduction in any medium, provided the original work is properly cited. 
from peanut hulls (Zhou et al., 2008). However, luteolin extraction is influenced by polyphenol-cell wall interactions that have been proposed to involve non-covalent associations, including hydrogen bonding, hydrophobic forces and ionic interactions, all of which can be affected by extraction conditions of temperature, time and $\mathrm{pH}$ (Boonmee, 2012; Phan et al., 2016). Therefore, it is necessary to break the bonds, by cleavage and cell wall disruption, for its release (Bohn, 2014).

Various methods, such as enzymatic hydrolysis (Chun et al., 2010), roasting (Taha et al., 2012), solid state fermentation (Liu et al., 2018) have been used to degrade the cellulose matrix of peanut shells. Efficient degradation has also been achieved through a combination of mechanical and thermoalkaline pre-treatments (Dahunsi et al., 2017).

The purpose of this study was to determine the optimal conditions of temperature and extraction solvent concentrations for luteolin extraction from peanut hulls. In addition, the antioxidant component contents and antioxidant capacities of extracts were measured. The results of the study are intended to contribute to the extensive utilization of peanut hull waste by obtaining bioactive compounds prior to secondary processes such as biorefinery and composting.

\section{Materials and methods}

\section{Materials}

Peanuts were obtained from a local market in Gochang County, South Korea. Peanuts were washed and dried using a convection oven (FC-2D-2S, Universal Scientific Co., Shanghai, China) at $60^{\circ} \mathrm{C}$ until a moisture content of $7 \%$ was reached. They were then sorted and shelled. Dried shells were crushed into a powder, passed through a 40- mesh sieve and placed in storage at $4^{\circ} \mathrm{C}$ until analysed. Gallic acid, ascorbic acid, quercetin, 2,2-diphenyl-1- picrylhydrazyl (DPPH), 2,2'-azino-bis(3-ethylbenzothiazoline- 6-sulphonic acid) (ABTS), aluminium chloride hexahydrate and sodium carbonate were purchased from Sigma Chemical Co. (St. Louis, MO, USA). Folin-Ciocalteu reagent was acquired from Junsei Chemical Co. Ltd. (Tokyo, Japan). Luteolin was purchased from Wako Chemicals Inc. (Richmond, VA, USA) and HPLC-grade ethyl alcohol, acetonitrile, glacial acetic acid and water were purchased from Fisher Scientific Inc. (Fair Lawn, NJ, USA).

\section{Extraction and preliminary testing}

During preliminary testing, $3 \mathrm{~h}$ and $12 \mathrm{~h}$ extractions were performed to select a basis for an extraction time. One gram of peanut hull powder was extracted in $50 \mathrm{~mL}$ of solvent for $3 \mathrm{~h}$ under reflux extraction. For comparison, conventional stirring was also performed for $3 \mathrm{~h}$.

To determine the best methanol concentration, peanut hull powder was extracted in methanol at concentrations of 20 , $40,60,80$ and $100 \%$. The hull powder was also extracted in distilled water as the control. These mixtures were extracted under reflux at equidistant temperatures of 25, 55 and $85^{\circ} \mathrm{C}$ in a water bath. Following this, sample extracts were filtered $(0.45 \mu \mathrm{m}$, polyvinylidene fluoride filters) and centrifuged at $10,000 \times g$ for $10 \mathrm{~min}$ at $4^{\circ} \mathrm{C}$. Supernatants were collected for subsequent analyses.

\section{Total phenolics content (TPC) measurement}

The TPC of the crude methanolic extracts were analysed using the Folin-Ciocalteu method with some modifications. One milliliter of sample extract was mixed with $5 \mathrm{~mL}$ of Folin-Ciocalteu reagent and let to stand for $3 \mathrm{~min}$. Four milliliters of $7.5 \%$ sodium carbonate was added and the mixture was developed in the dark before its absorbance was read. Gallic acid solution with a series of concentrations was used as the standards. The absorbance was measured at a wavelength of $765 \mathrm{~nm}$ with the UV-1700 PharmaSpec UV-visible spectrophotometer (Shimadzu Scientific, Kyoto, Japan). The TPC was expressed as $\mathrm{mg}$ of gallic acid equivalent per $100 \mathrm{~g}$ dry peanut hull powder.

\section{Total flavonoid content (TFC) measurement}

The TFC of the peanut hull extracts was measured using the aluminium chloride colorimetric method (Kalita et al., 2013) with some modifications. One millilitre of sample extract was mixed with $150 \mu \mathrm{L}$ of $5 \%$ sodium nitrate. This was left at room temperature for $5 \mathrm{~min}$ and $300 \mu \mathrm{L}$ of aluminium chloride hexahydrate was then added. The mixture was then let to stand for $6 \mathrm{~min}$. One millilitre of $1 \mathrm{M}$ sodium hydroxide was added and mixed with $550 \mu \mathrm{L}$ of water prior to reading the absorbance. Quercetin was used as the standard, prepared in $95 \%$ ethanol. Absorbance was measured at $510 \mathrm{~nm}$ and TFC was expressed as $\mathrm{mg}$ of quercetin equivalent per $100 \mathrm{~g}$ dry peanut hull powder. 


\section{ABTS radical-scavenging assay}

Thirty microliters of sample extract was mixed with $3 \mathrm{~mL}$ of $2.45 \mathrm{mM}$ prepared ABTS (having an absorbance of $0.7 \pm 0.02$ ) and let to stand in the dark for $6 \mathrm{~min}$. Absorbance was measured at a wavelength of $734 \mathrm{~nm}$ and the scavenging activity was determined according to the following formula:

$$
\begin{aligned}
\text { Scavenging activity }(\%)= & {\left[\left(\mathrm{A}_{734 \text { control }}-\mathrm{A}_{734 \text { sample }}\right)\right.} \\
& \left./\left(\mathrm{A}_{734} \text { control }\right)\right] \times 100
\end{aligned}
$$

Varying concentrations of L-ascorbic acid were used to produce a standard curve from which the $\mathrm{IC}_{50}$ value was determined, expressed as $\mu \mathrm{g} / 100 \mathrm{mg}$ vitamin $\mathrm{C}$ equivalent antioxidant capacity (VCEAC).

\section{DPPH radical-scavenging assay}

One hundred microliters of extract was mixed with $2 \mathrm{~mL}$ of $100 \mu \mathrm{M}$ DPPH solution and left to develop in the dark for $20 \mathrm{~min}$. Absorbance was measured at $515 \mathrm{~nm}$ and the scavenging activity was determined according to the formula:

$$
\begin{aligned}
\text { Scavenging activity }(\%)= & {\left[\left(\mathrm{A}_{515} \text { control }-\mathrm{A}_{515 \text { sample }}\right)\right.} \\
& \left./\left(\mathrm{A}_{515} \text { control }\right)\right] \times 100
\end{aligned}
$$

Varying concentrations of L-ascorbic acid were used to produce a standard curve from which the $\mathrm{IC}_{50}$ value was determined, expressed as $\mu \mathrm{g} / 100 \mathrm{mg}$ VCEAC.

\section{High performance liquid chromatography (HPLC) of luteolin analysis}

The analysis of luteolin standards and peanut extracts was carried out on a Waters Alliance e2695 Separations Module (Waters Co., MA, USA) using a Waters 2998 Photodiode array detector. The machine was equipped with Empower software (Europa Science Ltd., Cambridge, UK) and compounds were separated on a C18 reverse-phase column maintained at ambient temperature. The mobile phase had a constant flow rate of $0.80 \mathrm{~mL} / \mathrm{min}$ and was used with two solvents (A and B). Solvent A was $0.1 \%$ formic acid in water (HPLC grade) and solvent B was $80 \%$ acetonitrile and $20 \%$ acetic acid. The elution conditions were as follows: $15-40 \% \mathrm{~B}$ for $30 \mathrm{~min}, 40-100 \% \mathrm{~B}$ from $30-40 \mathrm{~min}$, and $100 \%$ B from $40-47 \mathrm{~min}$. The injection volume was $20 \mu \mathrm{L}$ and detection was at $263 \mathrm{~nm}$.

\section{Optimization and statistical analysis}

Under response surface methodology, the Central Composite Design was used to determine the optimal conditions of the controlled parameters at which the extracts

\begin{tabular}{|c|c|c|c|c|c|}
\hline \multirow{2}{*}{\multicolumn{2}{|c|}{ Factors }} & \multicolumn{4}{|c|}{ Levels } \\
\hline & & \multicolumn{2}{|c|}{ High $(-1)$} & Medium (0) & Low $(+1)$ \\
\hline \multicolumn{2}{|c|}{ Methanol concentration $(\%)$} & \multicolumn{2}{|c|}{60} & 80 & 100 \\
\hline \multicolumn{2}{|c|}{ Temperature $\left({ }^{\circ} \mathrm{C}\right)$} & \multicolumn{2}{|c|}{25} & 55 & 85 \\
\hline \multicolumn{6}{|c|}{ Final equation in coded factors for response variables $(\mathrm{Y})$} \\
\hline & Luteolin & TPC & TFC & ABTS & DPPH \\
\hline$\beta_{0}$ & +149.87 & $+1,249.52$ & +879.01 & +45.30 & +63.20 \\
\hline A & +34.80 & +420.10 & +418.60 & +19.29 & +18.12 \\
\hline $\mathrm{B}$ & +6.41 & -69.80 & -158.03 & -5.53 & -5.18 \\
\hline $\mathrm{AB}$ & +0.2517 & -35.53 & -66.07 & -4.08 & -2.94 \\
\hline $\mathrm{A}^{2}$ & -4.65 & +43.10 & +240.85 & +7.10 & +0.4602 \\
\hline $\mathrm{B}^{2}$ & -36.47 & -224.75 & -279.69 & -9.83 & -12.89 \\
\hline
\end{tabular}
would exhibit high antioxidant potential. The two factors were applied at three levels (Table 1).

Table 1. Factors and levels of the response surface methodology

Where: $\beta_{0}$ is intercept, $\mathrm{A}$ is temperature, $\mathrm{B}$ is methanol concentration. 
The quality of the model was fitted onto the quadratic model as:

$$
Y=\beta_{0}+\sum_{i=1}^{k} \beta_{i} X_{i}+\sum_{i=1}^{k} \beta_{i i} X_{i}^{2}+\sum_{i<j}^{k} \beta_{i j} X_{i} X_{j}+e
$$

where: $\mathrm{Y}=$ response variable; $\beta_{0}=$ intercept; $\beta_{i}=$ first order coefficient of the model where $i=1,2 \cdots k) ; \beta_{i j}=$ interaction effect; $\beta_{i i}=$ quadratic coefficients of $\mathrm{X}_{i}$ and $\varepsilon=$ random error.

The data collected for the responses $(Y)$ were luteolin, TPC, TFC, ABTS and DPPH activity, and these were analysed via Stat-Ease Design-Expert software package (11.1.2.0, Stat-Ease Inc., Minneapolis, USA) and SigmaPlot (13, Systat Software Inc., California, USA). Mean separations were obtained using Tukey's student test at $\mathrm{p} \leq 0.05$.

\section{Results and discussion}

The recovery of polyphenolic compounds from plant tissue often employs the use of polar solvents and methanol has been shown to typically be efficient in the extraction of compounds with lower molecular weights (Do et al., 2014). In addition, higher amounts of polyphenols can be extracted with an increase in the polarity of the solvent. In addition, higher amounts of polyphenols can be extracted with an increase in the polarity of the solvent. A report on the various solvent extracts of phenolics from moringa leaves (Siddhuraju and Becker, 2003) stated that methanol was the most ideal solvent for phenolic extraction because of its high polarity and the phenolic compound solubility of plant components.

During preliminary testing, 3 and $12 \mathrm{~h}$ extractions were performed to select an extraction time and there were no increases in the luteolin content after $12 \mathrm{~h}$. Extracts from conventional stirring after $3 \mathrm{~h}$ were $122.13 \mathrm{mg} / 100 \mathrm{~g}$ while $12 \mathrm{~h}$ extracts had $119.38 \mathrm{mg} / 100 \mathrm{~g}$ luteolin. Twelve-hour reflux extracts had a luteolin content of $173.46 \mathrm{mg} / 100 \mathrm{~g}$ and three-hour extracts had a content of $174.03 \mathrm{mg} / 100 \mathrm{~g}$. For both extraction methods, $3 \mathrm{~h}$ was selected as the extraction time.

In this study, at $80 \%$ methanol concentration, luteolin, polyphenols and flavonoid content were found to be the highest (Fig. 1). This variation was likely due to the increased efficiency of the extraction of phenolic compounds and flavonoids which is influenced by the polarity of the compounds. To confirm this, conventional stirring was performed using $80 \%$ methanol and the antioxidant compound contents and capacities of the extracts were determined. The luteolin content, antioxidant contents and antioxidant capacities of reflux extracts generated at $85^{\circ} \mathrm{C}$ in $80 \%$ methanol were generally higher than that of conventional stirring. The luteolin contents of the extracts were $122.13 \mathrm{mg} / 100 \mathrm{~g}$ from conventional stirring and $174.03 \mathrm{mg} / 100 \mathrm{~g}$ from reflux extraction. For the experimental means from the reflux extracts, the TPC was $2,049.51 \mathrm{mg}$ GAE/100 g; TFC was $1,817.86 \mathrm{mg}$ QE/100 g; ABTS scavenging activity was $67.21 \%$, and DPPH scavenging activity was $81.10 \%$. For conventionally stirred extracts, TPC was $844.75 \mathrm{mg}$ GAE/100 g; TFC was $780.0 \mathrm{mg}$ QE/100 g; ABTS radical-scavenging activity was $41.13 \%$, and DPPH scavenging activity was $62.48 \%$. The $\mathrm{IC}_{50}$ values for ABTS and DPPH radicals were $104.18 \mu \mathrm{g} / \mathrm{mL}$ and $83.08 \mu \mathrm{g} / \mathrm{mL}$, respectively.

Extractions performed at room temperature had the lowest contents for all five parameters measured and raising the temperature led to an increase in the luteolin extracted as well as the antioxidant contents and capacities. Refluxing at room temperature $\left(25^{\circ} \mathrm{C}\right)$ produced a luteolin content of $107.75 \mathrm{mg} / 100 \mathrm{~g}$ which was lower than that of stirring. However, the reflux extract at $85^{\circ} \mathrm{C}(174.03 \mathrm{mg} / 100 \mathrm{~g})$ increased the luteolin content by $42.50 \%$. Overall, higher temperatures led to higher luteolin and antioxidant contents, which was a different finding from vortex mixing which exhibited no improvements upon comparing room temperature and $50^{\circ} \mathrm{C}$ extractions (Lee et al., 2008).

The processes of heating and hydrolysis reactions are both able to increase the polyphenol content during extractions by releasing compounds that were previously bound to cell wall components. Heat in particular liberates and activates low molecular weight polymeric subunits (Hatam et al., 2013) which allows higher temperatures to be used in extractions without degrading the desired phenolic compounds. In addition to this, heating under reflux provides continual mixing of the solution, improving the extraction efficiency. The higher temperatures result in increased diffusion and improved solubility and the kinetic energy is distributed at a molecular level, which stirring 

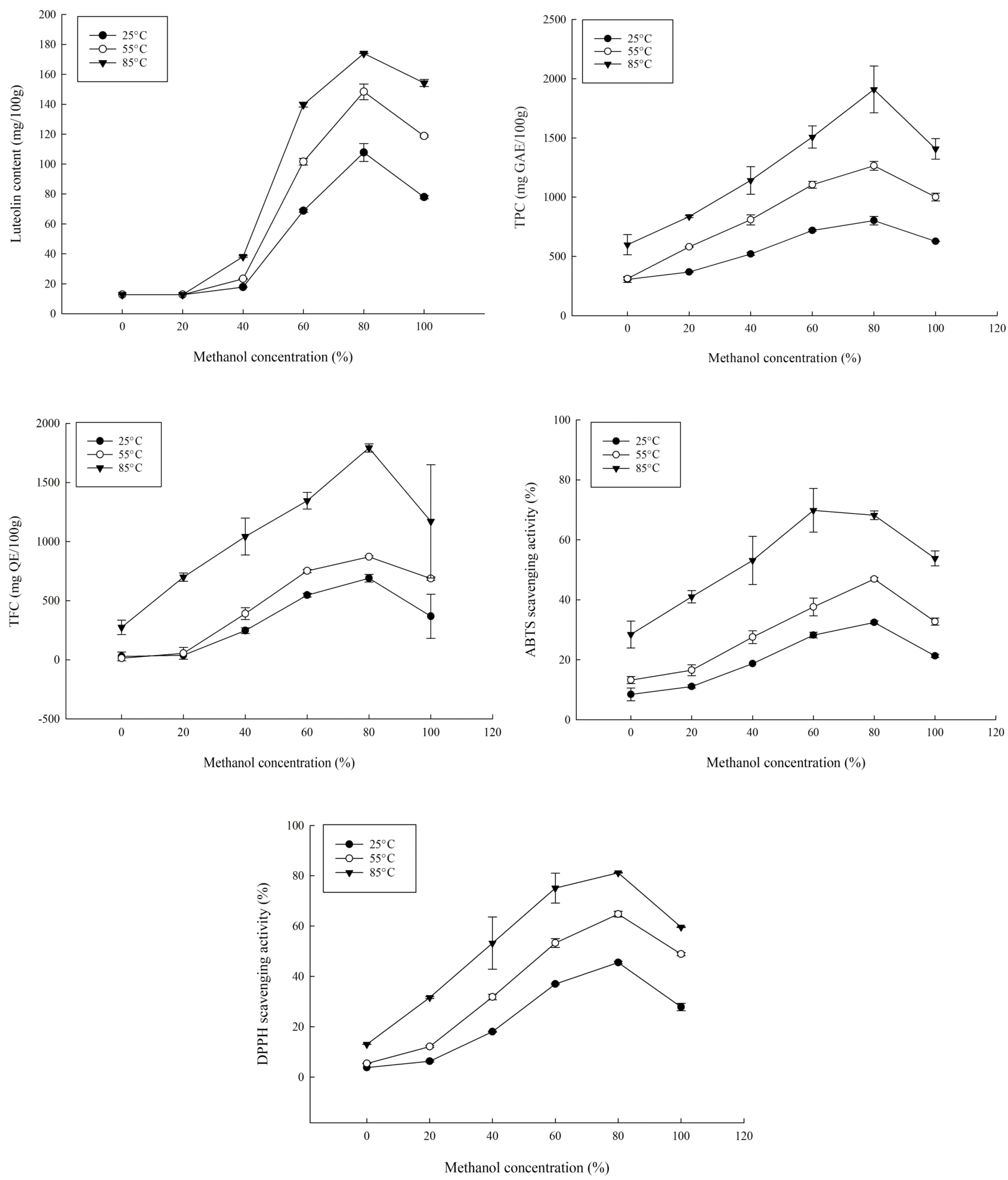

Fig. 1. Effect of methanol concentration and extraction temperature on luteolin (A), total phenolics content (B, TPC), total flavonoid content (C, TFC), ABTS radical cation assay (D), and DPPH radical assay (E) of peanut hull extracts.

The vertical bars represent mean \pm SD $(n=2)$. Significant differences between means of each group (by temperature) are denoted by letters. Means with the same letters are not significantly different $(p>0.05)$. 
alone may not achieve.

For all studied parameters, a concentration of $80 \%$ methanol and temperature of $85^{\circ} \mathrm{C}$ increased the phenolic compounds as well as their antioxidant capacity (Fig. 1). There were significant differences between the temperature and methanol concentrations of the extracts $(p<0.05)$, with that of temperature being highly significant $(p<0.01)$ due to enhanced extractions and recovery of phenolic compounds through the increase of the diffusion coefficient and solid to solvent solubility. However, prolonged exposure or treatment with high temperatures could also lead to deterioration of active compounds which is likely the cause of the eventual decrease.

At all temperatures, the highest yield of compounds was obtained from the $80 \%$ methanol extracts and while some compounds could be water-soluble, the efficiency of water as an extraction solvent, unaided by other factors like temperature, has been shown to be lacking in previous studies (Boonmee, 2012; Do et al., 2014; Kalita et al., 2013).

\section{Optimization}

To determine the optimum extraction conditions of the peanut hulls, the central composite design was used (Table 1, Table 2). The lack of fit for the measured parameters was insignificant relative to the pure error and this was tested against each response. Non-significant lack-of-fit is the preferred state of the model and so, implied the model fit for the responses. For TPC, due to the wide range present between the experimental values, the data was transformed and analyzed. The results obtained showed that there was less efficient extraction occurring at lower temperatures and lower methanol concentrations for all responses (Table 3, Table 4). At $25^{\circ} \mathrm{C}$, luteolin ranged from $68-112 \mathrm{mg} / 100 \mathrm{~g}$ while TPC, TFC, ABTS and DPPH ranges were 628.22828.22 mg GAE/100 g, 235.81-713.23 mg QE/100 g, 20.93$32.08 \%$ and $28.92-45.88 \%$, respectively. The observed tendency showed that $100 \%$ methanol had the least antioxidant activity and content while $80 \%$ methanol had the highest at that temperature. This was similarly the case at

Table 2. Fit summary of individual parameters (quadratic model) for quality prediction of peanut hull

\begin{tabular}{cccccc}
\hline Source & $\begin{array}{c}\text { Sequential } \\
\text { p-value }\end{array}$ & F-value & $\begin{array}{c}\text { Lack of fit } \\
\text { p-value }\end{array}$ & Adjusted R $^{2}$ & Predicted R $^{2}$ \\
\hline Luteolin & $<0.0001$ & 1.53 & 0.2717 & 0.9625 & 0.9509 \\
Total phenolic content ${ }^{1)}$ & $<0.0001$ & 2.36 & 0.1399 & 0.9941 & 0.9883 \\
Total flavonoid content & 0.0355 & 1.09 & 0.4016 & 0.7987 & 0.9693 \\
ABTS scavenging activity \% & 0.0005 & 1.16 & 0.3766 & 0.9640 \\
DPPH scavenging activity \% & $<0.0001$ & 1.49 & 0.2819 & 0.9800 & 0.9582 \\
\hline
\end{tabular}

\footnotetext{
${ }^{1)}$ Total phenolics content was analyzed under 'Inverse transform' conditions due to wide range. $p$-value $\leq \alpha$ : The lack-of-fit is statistically significant.
}

Table 3. Central composite design for the extraction of luteolin and antioxidant activities from peanut hull

\begin{tabular}{cccccc}
\hline Run & $\begin{array}{c}\mathrm{X}_{1} \\
(\%)\end{array}$ & $\begin{array}{c}\mathrm{X}_{2} \\
\left({ }^{\circ} \mathrm{C}\right)\end{array}$ & $\begin{array}{c}\text { Luteolin } \\
(\mathrm{mg} / 100 \mathrm{~g})\end{array}$ & $\begin{array}{c}\mathrm{TPC} \\
(\mathrm{mg} \text { GAE/100 g) }\end{array}$ & $\begin{array}{c}\mathrm{TFC} \\
(\mathrm{mg} \mathrm{QE} / 100 \mathrm{~g}\end{array}$ \\
\hline 1 & 60 & 85 & 138.59 & $1,441.75$ & $1,296.43$ \\
2 & 60 & 85 & 140.87 & $1,573.79$ & $1,396.43$ \\
3 & 100 & 25 & 78.73 & 628.22 & 235.81 \\
4 & 80 & 55 & 144.63 & $1,291.96$ & 865.16 \\
5 & 100 & 85 & 152.57 & $1,346.60$ & 832.14 \\
6 & 60 & 25 & 68.04 & 713.27 & 535.81 \\
7 & 80 & 55 & 152.07 & $1,237.76$ & 878.07 \\
\hline
\end{tabular}


(continued)

\begin{tabular}{|c|c|c|c|c|c|}
\hline Run & $\begin{array}{l}\mathrm{X}_{1} \\
(\%)\end{array}$ & $\begin{array}{l}\mathrm{X}_{2} \\
\left({ }^{\circ} \mathrm{C}\right)\end{array}$ & $\begin{array}{l}\text { Luteolin } \\
(\mathrm{mg} / 100 \mathrm{~g})\end{array}$ & $\begin{array}{c}\text { TPC } \\
(\mathrm{mg} \mathrm{GAE} / 100 \mathrm{~g})\end{array}$ & $\begin{array}{c}\text { TFC } \\
(\mathrm{mg} \mathrm{QE} / 100 \mathrm{~g}\end{array}$ \\
\hline 9 & 100 & 25 & 77.12 & 627.29 & 500.32 \\
\hline 10 & 60 & 25 & 69.54 & 725.42 & 558.39 \\
\hline 11 & 100 & 85 & 155.92 & $1,468.93$ & $1,510.71$ \\
\hline 12 & 80 & 55 & 168.08 & $1,266.78$ & 870.04 \\
\hline 13 & 80 & 55 & 151.29 & $1,244.07$ & 867.41 \\
\hline 14 & 80 & 55 & 153.74 & $1,265.84$ & 867.49 \\
\hline 15 & 100 & 55 & 118.27 & $1,024.67$ & 697.42 \\
\hline 16 & 80 & 25 & 103.49 & 777.76 & 668.07 \\
\hline 17 & 60 & 55 & 100.03 & $1,125.61$ & 742.58 \\
\hline 18 & 80 & 85 & 173.95 & $2,049.51$ & $1,817.86$ \\
\hline
\end{tabular}

Where $\mathrm{X}_{1}$, methanol concentration; $\mathrm{X}_{2}$, temperature.

Table 4. Central composite design for the scavenging activity factors and responses from peanut hull extracts

\begin{tabular}{|c|c|c|c|c|c|c|}
\hline Run & $\begin{array}{c}X_{1} \\
(\%)\end{array}$ & $\begin{array}{c}\mathrm{X}_{2} \\
\left({ }^{\circ} \mathrm{C}\right)\end{array}$ & $\begin{array}{c}\text { ABTS scavenging } \\
\text { activity }(\%)\end{array}$ & $\begin{array}{l}\text { ABTS VCEAC } \\
(\mu \mathrm{g} / \mathrm{mL})\end{array}$ & $\begin{array}{c}\text { DPPH scavenging } \\
\text { activity }(\%)\end{array}$ & $\begin{array}{c}\text { DPPH VCEAC } \\
(\mu \mathrm{g} / \mathrm{mL})\end{array}$ \\
\hline 1 & 60 & 85 & 64.71 & 355.94 & 70.90 & 117.52 \\
\hline 2 & 60 & 85 & 75.00 & 412.54 & 79.30 & 131.37 \\
\hline 3 & 100 & 25 & 20.93 & 115.13 & 28.92 & 48.33 \\
\hline 4 & 80 & 55 & 47.29 & 260.12 & 65.59 & 108.77 \\
\hline 5 & 100 & 85 & 52.06 & 286.36 & 59.70 & 99.06 \\
\hline 6 & 60 & 25 & 27.56 & 151.60 & 36.76 & 61.25 \\
\hline 7 & 80 & 55 & 46.54 & 256.00 & 64.02 & 106.18 \\
\hline 8 & 80 & 55 & 46.40 & 255.23 & 64.46 & 106.91 \\
\hline 9 & 100 & 25 & 21.69 & 119.31 & 26.86 & 44.93 \\
\hline 10 & 60 & 25 & 28.92 & 159.08 & 37.25 & 62.06 \\
\hline 11 & 100 & 85 & 55.59 & 305.78 & 59.50 & 98.73 \\
\hline 12 & 80 & 55 & 47.32 & 260.29 & 65.99 & 109.43 \\
\hline 13 & 80 & 55 & 47.64 & 262.05 & 66.12 & 109.65 \\
\hline 14 & 80 & 55 & 46.48 & 255.67 & 66.01 & 109.46 \\
\hline 15 & 100 & 55 & 33.58 & 184.71 & 49.31 & 81.94 \\
\hline 16 & 80 & 25 & 32.83 & 180.58 & 45.20 & 75.16 \\
\hline 17 & 60 & 55 & 39.76 & 218.70 & 54.51 & 90.51 \\
\hline 18 & 80 & 85 & 67.21 & 369.69 & 81.10 & 134.34 \\
\hline
\end{tabular}

Where $X_{1}$, methanol concentration; $X_{2}$, temperature. 
$85^{\circ} \mathrm{C}$, where the response variables ranges were 152.57 $174.12 \mathrm{mg} / 100 \mathrm{~g}$ for luteolin content; 1,346.6-1,769.9 mg GAE/100 $\mathrm{g}$ for TPC; 832.14-1,767.86 mg QE/100 $\mathrm{g}$ for TFC; 52.06-75\% ABTS scavenging activity, and 59.7-81.3\% DPPH scavenging activity. These values were from lowest at $100 \%$ methanol to highest at $80 \%$ methanol, with the exception of ABTS scavenging activity which was highest at $60 \%$ methanol.

From the CCD, the predicted optimal conditions for maximum yield of luteolin, were: $81.22^{\circ} \mathrm{C}$ and $87.47 \%$ methanol for a predicted value of $174.51 \mathrm{mg} / 100 \mathrm{~g}$ (Table 5). These experimental conditions were applied as $81^{\circ} \mathrm{C}$ and $87.5 \%$ methanol, and to verify the accuracy of the predicted optimal parameters from the $\mathrm{CCD}\left(\mathrm{X}_{1}: 87.5 \%\right.$ and $\left.\mathrm{X}_{2}: 81^{\circ} \mathrm{C}\right)$, the luteolin content was determined under these optimal conditions. The percentage difference between the values obtained by the model were all below $10 \%$ which confirmed the predictability of the model for the extractions of peanut hulls. To confirm optimization, extraction was performed at $90^{\circ} \mathrm{C}$ and the luteolin content decreased to $68.56 \mathrm{mg} / 100 \mathrm{~g}$, suggesting possible degradation at that temperature.

The interaction effects of the factors on the compounds and activities was shown on surface plots (Fig. 2) that expressed the interactive relationships between the methanolic concentration and temperature of the different extracts. Higher temperatures can enable the degradation of the cell walls of the peanut hulls but also increase the degradation of flavonoids like luteolin, in addition to degrading thermal labile phenolic compounds. With the exception of the methanol concentration, there were significantly positive correlations between the response variables as well as between the response variables and increasing extraction temperature. The parameters all had significant correlations between them $\left(\mathrm{R}^{2}>0.70\right)$. The antioxidant components of phenolic and flavonoid compounds were reflected in the linear correlations between the parameters of phenolics, flavonoids, ABTS scavenging activity and DPPH scavenging activity. The increased luteolin content and antioxidant potential of peanut hull extracts can enhance the stability of various products if applied against primary oxidation.

\section{Conclusion}

Extracting luteolin under reflux from peanut hulls is a simple method with relatively low costs that, in succession, can exhaustively utilize peanut waste biomass in the production chain. Temperature and methanolic concentrations were optimized for increased extraction efficiency with the added benefit of increasing the antioxidant content and activity of the extracts and the extracted luteolin was increased by $42.50 \%$. The results of the study will contribute to the extensive utilization of peanut hull waste by obtaining bioactive compounds prior to secondary processes such as biorefinery or composting facilities.

\section{Conflict of interests}

The authors declare no potential conflict of interest.

\section{ORCID}

Inonge N. Siziya https://orcid.org/0000-0002-0014-2557

Young-Soo Kim https://orcid.org/0000-0003-1308-4453

Table 5. Predicted and experimental values at optimized conditions ${ }^{1)}$ for quality parameters

\begin{tabular}{cccc}
\hline Selected parameter & Predicted value & Experimental value & $\begin{array}{c}\text { \% difference from } \\
\text { predicted }\end{array}$ \\
\hline Luteolin & $174.51 \mathrm{mg} / 100 \mathrm{~g}$ & $172.35 \pm 1.25 \mathrm{mg} / 100 \mathrm{~g}$ & 1.25 \\
TPC & $1,667.23 \mathrm{mg} \mathrm{GAE} / 100 \mathrm{~g}$ & $1,666.29 \pm 0.06 \mathrm{mg} \mathrm{GAE} / 100 \mathrm{~g}$ & 0.06 \\
TFC & $1,411.90 \mathrm{mg} \mathrm{QE} / 100 \mathrm{~g}$ & $1,410.70 \pm 0.09 \mathrm{mg} \mathrm{QE} / 100 \mathrm{~g}$ & 0.09 \\
ABTS & $62.27 \%$ & $61.38 \pm 1.46 \%$ & 1.46 \\
DPPH & $74.68 \%$ & $72.77 \pm 2.62 \%$ & 2.62 \\
\hline
\end{tabular}

\footnotetext{
${ }^{1)}$ Optimized parameters: $81^{\circ} \mathrm{C} ; 87.5 \%$ methanol. Confidence $=95 \%$, Population $=99 \%$.
} 
(A)

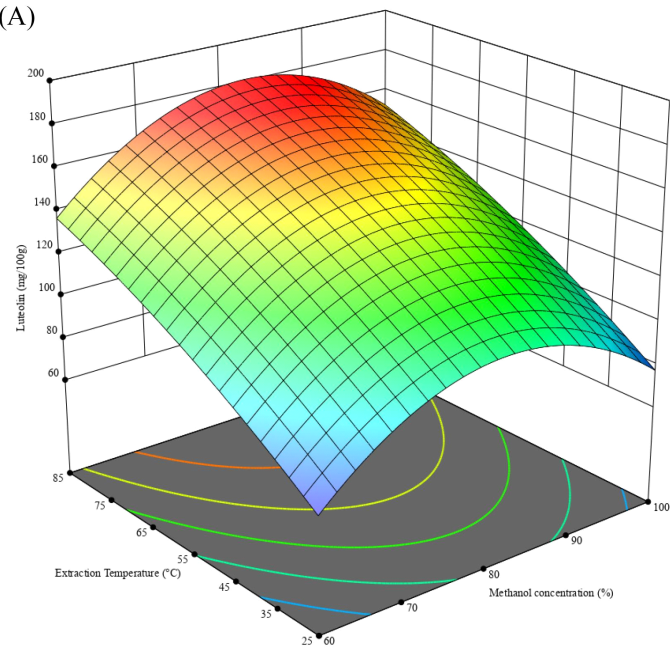

(C)

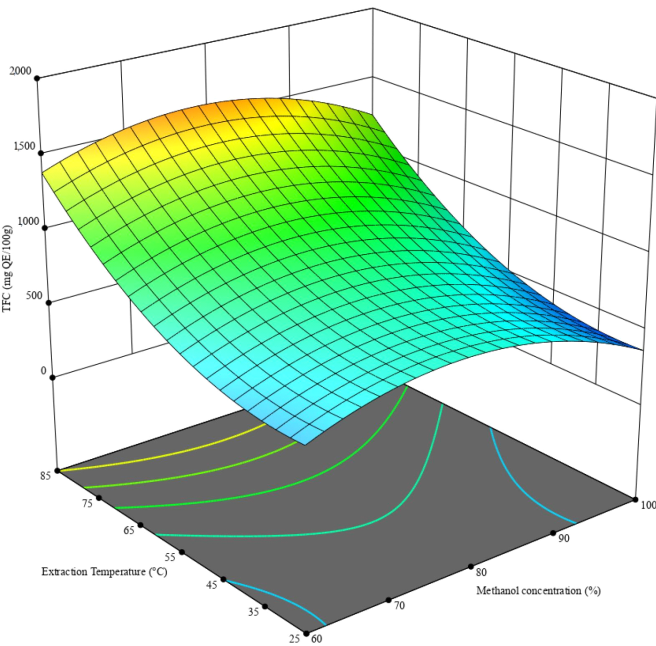

(B)

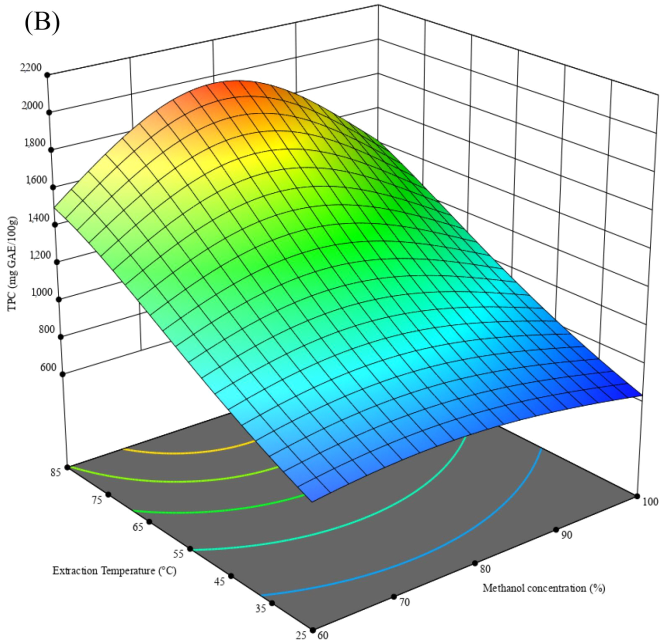

(D)

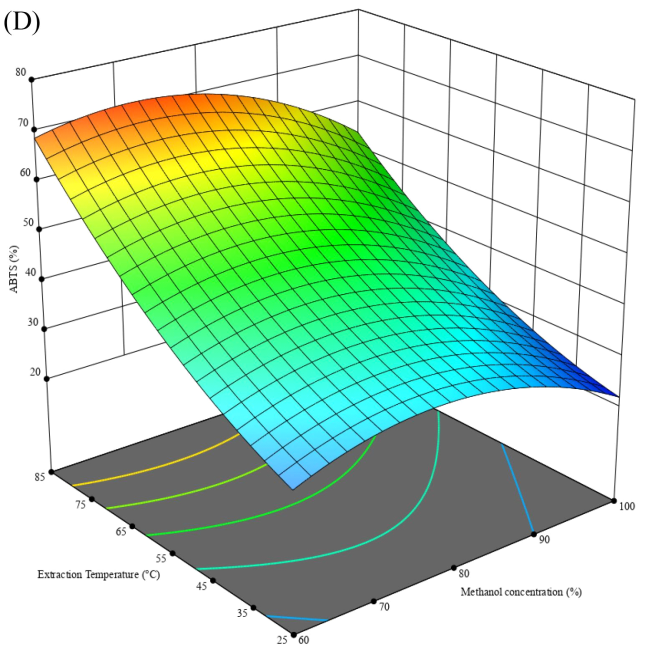

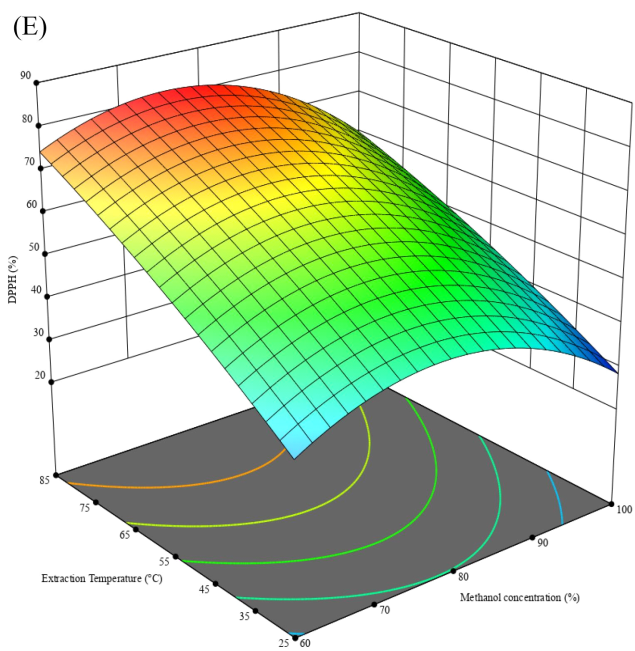

Fig. 2. Response surface plots showing the effect of methanol concentration and extraction temperature on the five measured response variables.

A, luteolin content; B, total phenolic content; C, total flavonoid content; D, ABTS scavenging activity; E, DPPH scavenging activity. 


\section{References}

Adhikari B, Dhungana SK, Ali MW, Adhikari A, Kim ID, Shin DH. Antioxidant activities, polyphenol, flavonoid, and amino acid contents in peanut shell. J Saudi Soc Agric Sci, 18, 437-442 (2018)

Bohn T. Dietary factors affecting polyphenol bioavailability. Nutr Rev, 72, 429-452 (2014)

Boonmee A. Hydrolysis of various thai agricultural biomasses using the crude enzyme from Aspergillus aculeatus Iizuka FR60 isolated from soil. Braz J Microbiol, 43, 456-466 (2012)

Chun W, Lingling C, Shujuan C. Technology of extracting luteolin from solid waste of peanut hulls. Paper presented at International Conference on Challenges in Environmental Science and Computer Engineering, March 6, Wuhan, China (2010)

Dahunsi S, Oranusi S, Efeovbokhan VE. Optimization of pretreatment, process performance, mass and energy balance in the anaerobic digestion of Arachis hypogaea (peanut) hull. Energ Convers and Manage, 139, 260-275 (2017)

Do QD, Angkawijaya AE, Tran-Nguyen PL, Huynh LH, Soetaredjo FE, Ismadji $\mathrm{S}, \mathrm{Ju} \mathrm{YH}$. Effect of extraction solvent on total phenol content, total flavonoid content, and antioxidant activity of Limnophila aromatica. J Food Drug Anal, 22, 296-302 (2014)

Hatam SF, Suryanto E, Abidjulu J. Aktivitas antioksidan dari ekstrak kulit nanas (Ananas comosus (L) Merr). Pharmacon, 2, 2302-2493 (2013)

Kalita P, Tapan BK, Pal TK, Kalita R. Estimation of total flavonoids content (TFC) and anti oxidant activities of methanolic whole plant extract of Biophytum sensitivum Linn. J Drug Deliv Ther, 3, 33-37 (2013)

Lee JH, Baek IY, Ha TJ, Choung MG, Ko JM, Oh SK, Kim HT, Ryu HW, Park KY, Park KH. Identification and characterization of phytochemicals from peanut (Arachis hypogaea L.) pods. Food Sci Biotechnol, 17, 475-482 (2008)
Lee YY, Bae SP, Lee CK. Antioxidant activities of peanut (Arachis hypogaea L.) skins methanol extract of different color. Paper presented at The Korean Society of Medicinal Crop Science Spring Conference, April 28, Jeju, Korea (2011)

Liu J, Wang Z, Li H, Hu C, Raymer P, Huang Q. Effect of solid state fermentation of peanut shell on its dye adsorption performance. Bioresour Technol, 249, 307314 (2018)

Phan ADT, D'arcy BR, Gidley MJ. Polyphenol-cellulose interactions: Effects of $\mathrm{pH}$, temperature and salt. Int $\mathrm{J}$ Food Sci Technol, 51, 203-211 (2016)

Qiu J, Xin X, Chen X, Zhao S, Zhou Q, Yang J, Liu X, Wang J, Chen L. Phenolics quantitative and their chemical fingerprint analysis in peanut shells. Biomed $\mathrm{J}$ Sci Tech Res, 11, 1-7 (2018)

Rivilli PL, Alarcón R, Isasmendi GL, Pérez JD. Stepwise isothermal fast pyrolysis (SIFP) part II. SIFP of peanut shells - Antifungal properties of phenolic fractions. BioResources, 7, 112-117 (2012)

Siddhuraju P, Becker K. Antioxidant properties of various solvent extracts of total phenolic constituents from three different agroclimatic origins of drumstick tree (Moringa oleifera Lam.) leaves. J Agric Food Chem, 51, 21442155 (2003)

Taha FS, Wagdy SM, Singer FA. Comparison between antioxidant activities of phenolic extracts from different parts of peanut. Life Sci J, 9, 207-215 (2012)

Win MM, Abdul Hamid A, Baharin BS, Farooq A, Sabu MC, Pak-Dek MS. Phenolic compounds and antioxidant activity of peanut's skin, hull, raw kernel and roasted kernel flour. Pak J Bot, 43, 1635-1642 (2011)

Zhao X, Chen J, Du F. Potential use of peanut by-products in food processing: A review. J Food Sci Technol, 49, 521-529 (2012)

Zhou P, Li LP, Luo SQ, Jiang HD, Zeng S. Intestinal absorption of luteolin from peanut hull extract is more efficient than that from individual pure luteolin. J Agric Food Chem, 56, 296-300 (2008) 